\title{
Low cycle fatigue and creep-fatigue response of the 316 Ti stainless steel
}

\author{
S.C.S.P. Kumar Krovvidi, Sunil Goyal, A. K. Bhaduri \\ Indira Gandhi Centre for Atomic Research, Kalpakekam- 603102, India \\ krovvidi@igcar.gov.in,goyal@igcar.gov.in,bhaduri@igcar.gov.in
}

ABSTRACT. SS 316Ti is widely used in bellows industry and is a good candidate material for high temperature bellows in sodium cooled fast reactor (SFR) systems. Typical operating temperature experienced by SFR systems is around $823 \mathrm{~K}$. Design of bellows for nuclear applications need to be in compliance with the standard design codes such as ASME section-III and RCC-MR. The fatigue data and cyclic stress strain curve of SS316Ti are not available in design codes such as RCC-MR or ASME section-III/NH. Hence, the material data required for high temperature design of bellows are generated experimentally. Initially, the basic tensile data such as yield strength, ultimate tensile strength and \% elongation of the material were obtained from tensile testing at $823 \mathrm{~K}$. Low cycle fatigue tests were carried out in strain controlled mode on SS316 Ti at $823 \mathrm{~K}$ different strain ranges in air and variation of number of cycles with strain range was obtained. Creep-fatigue interaction (CFI) experiment was also conducted at $823 \mathrm{~K}$ and strain amplitude of $\pm 0.4 \%$ with 1 minute hold time in peak tensile strain. The stress response (peak stress variation with number of cycles) of the material showed continuous hardening up to saturation followed by crack nucleation and final failure. The fatigue life was found to decrease with increase in strain range. The fatigue life decreased in presence of hold period in tension. The design fatigue curve for SS316 Ti at $823 \mathrm{~K}$ has been generated using the LCF data by incorporating factors of safety on strain and number of cycles. Cyclic stress strain curve was generated for the material at $823 \mathrm{~K}$. The tensile, LCF and CFI data generated will be useful in design of SS316Ti bellows for SFR systems.

KEYwORDS. SS 316Ti; Bellows; Low cycle fatigue; Creep-fatigue interaction.

\section{OPEN ACCESS}

Citation: Kumar Krovvidi, S.C.S.P., Goyal, S., Bhaduri, A. K., Low cycle fatigue and creepfatigue response of the 316 Ti stainless steel, Frattura ed Integrità Strutturale, 48 (2019) 577-584.

Received: 27.11 .2018

Accepted: 28.02.2019

Published: 01.04.2019

Copyright: (C) 2019 This is an open access article under the terms of the CC-BY 4.0, which permits unrestricted use, distribution, and reproduction in any medium, provided the original author and source are credited.

\section{INTRODUCTION}

3

16Ti stainless steel is a titanium-stabilized grade of Type 316 austenitic stainless steel. Type 316 stainless steels are generally susceptible to sensitization in the temperature range of $500^{\circ} \mathrm{C}$ to $850^{\circ} \mathrm{C}$ due to the formation of grain boundary chromium carbides resulting in reduction in corrosion resistance [1]. Resistance to sensitization is achieved 
in Type 316 Ti with titanium additions by the formation of titanium carbide against chromium carbide precipitation [1]. SS 316Ti is widely used in bellows industry and is a candidate material for the bellows operating at high temperature in sodium cooled fast reactor (SFR) systems [2]. Bellows are generally used in piping system to absorb the differential thermal expansions and in bellow-sealed valves to prevent the entry of the process fluid to external environment. Typical applications of the bellows are given in Fig. 1.

Bellows are subjected to pressure and movements (axial, lateral and angular). Bellows are specified mainly with their design pressure and fatigue life for the rated movements. Thickness of the bellows ply is decided based on the design pressure. However, the remaining design parameters such as pitch, depth of convolution, and number of convolutions are decided based on the fatigue life expectancy of the bellows.

Design of the bellows in conventional system is carried out by using standards of expansion joints manufacturer's association (EJMA) [3]. However, design methodology of the bellows SFR systems shall comply with standard design codes for nuclear systems such as RCC-MR or ASME boiler and pressure vessel code, section-III [4,5]. A typical operating temperature in SFR systems is around $550^{\circ} \mathrm{C}$. Design of the bellows against fatigue as per RCC-MR requires material properties such as cyclic stress-strain curve, design fatigue curve (strain range versus number of cycles). The material properties of SS316Ti are not available in RCC-MR.

Creep-fatigue interaction (CFI) testing is generally carried out by imposing strain hold in continuous cycle fatigue either in tension or compression or both. The presence of hold time results in stress relaxation which in turn leads to creep damage in the material. The response of materials to application of hold depends upon the microstructure, duration of hold, location of hold, environment and temperature. More deleterious effects of tensile hold compared to equal compressive hold have been observed in many materials such as austenitic stainless steels (SS 304, SS 316 and their modified grades) and some superalloys [6-11].

Very limited data exist on the mechanical properties of 316 Ti SS in open literature. The present investigation has been carried out to evaluate the mechanical properties such as tensile, low cycle fatigue, and creep-fatigue interaction of the material.
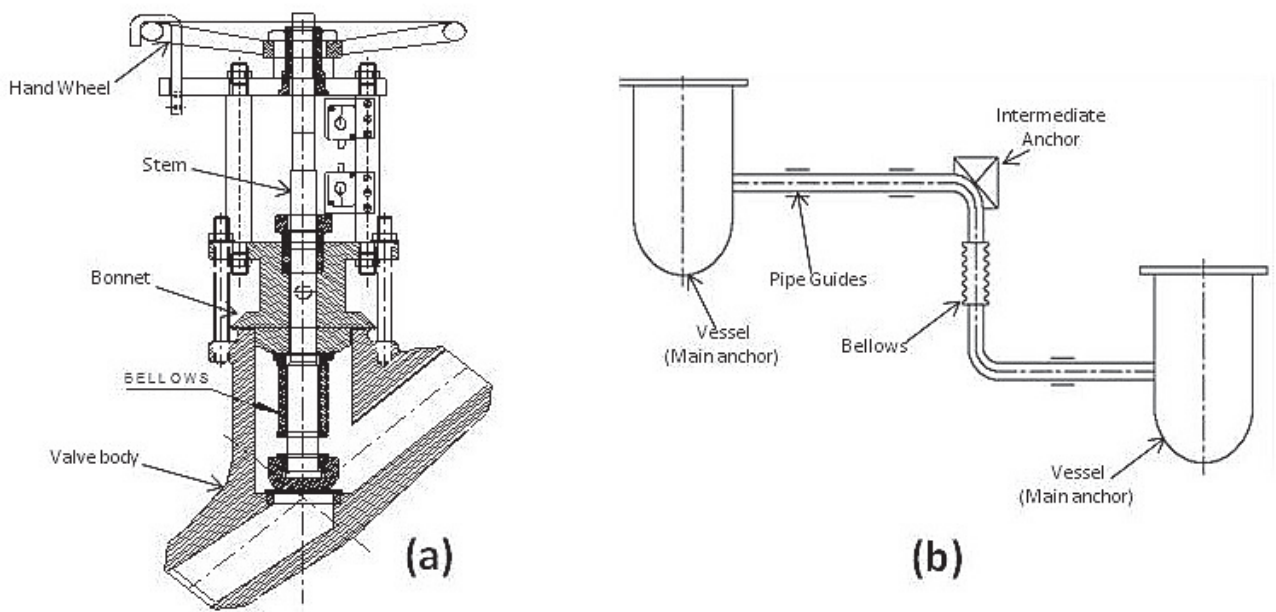

(b)

Figure 1: Typical applications of bellows in SFR systems (a) Bellows sealed sodium valve and (b) bellows in piping system to absorb thermal expansions.

\section{EXPERIMENTAL}

7 he 316Ti austenitic stainless steel (SS) has been used for the present investigation. The chemical composition of the material is shown in Tab. 1. The plate was received in solution annealed condition, with the chemical and the mechanical properties confirming to ASTM A240. The plate was heated to a temperature of $1311 \mathrm{~K}$ followed by water quenching. Tensile test was carried out at $823 \mathrm{~K}$ and at a strain rate of $3 \times 10^{-3} \mathrm{~s}^{-1}$ in air environment. The low cycle fatigue experiments were carried out on 316 Ti SS at different strain amplitudes ranging from $\pm 0.25 \%$ to $\pm 0.8 \%$ in air environment at a strain rate of $3 \times 10^{-3} \mathrm{~s}^{-1}$ and $823 \mathrm{~K}$. The gauge length and diameter of the specimen were $15 \mathrm{~mm}$ and 6 $\mathrm{mm}$, respectively. The schematic of specimen is shown in Fig. 2. All the tests were carried out in air under fully reversed, total axial strain control mode employing a symmetrical triangular strain-time waveform using DARTEC servo hydraulic 
fatigue testing system. The creep-fatigue interaction test was also conducted at total strain amplitude of $\pm 0.4 \%$ with 1 minute hold at peak tensile strain.

\begin{tabular}{lllllllllll}
\hline Element & $\mathrm{C}$ & $\mathrm{Mn}$ & $\mathrm{Si}$ & $\mathrm{Ni}$ & $\mathrm{Ti}$ & $\mathrm{Cr}$ & $\mathrm{Mo}$ & $\mathrm{S}$ & $\mathrm{P}$ & $\mathrm{Fe}$ \\
wt.\% & 0.018 & 1.89 & 0.27 & 10.81 & 0.19 & 16.9 & 2.14 & 0.001 & 0.04 & Bal. \\
\hline
\end{tabular}

Table 1: Chemical composition of 316Ti stainless steel (wt. \%)

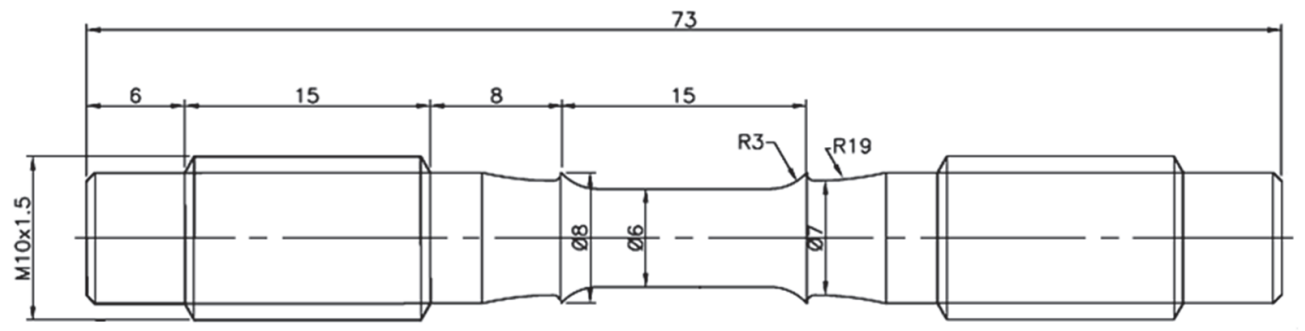

Figure 2: The schematic of specimen used for LCF and CFI testing.

\section{RESULTS AND DISCUSSION}

7 ensile test was carried out at $823 \mathrm{~K}$ and at a strain rate of $3 \times 10^{-3} \mathrm{~s}^{-1}$. The engineering stress-strain curve obtained from the tensile test is shown in Fig. 3. The tensile properties evaluated for the steel are given in Tab. 2.

Dynamic strain ageing (DSA) during tensile deformation is generally manifested as serrated yielding in the stressstrain curve, Fig. 1. The DSA occurs at certain strain rate and temperature ranges and is a characteristic of the material and its microstructure [12]. Generally, the DSA occurs due to the interaction between solute atoms and dislocations at temperature where the mobility of solute is sufficient to lock mobile dislocations [13]. The serrations in the tensile curve or hysteresis loops in fatigue associated with the repeated locking and unlocking of dislocations in solute atmospheres. Ganesan et al. studied the effect of nitrogen on DSA behaviour of 316 LN SS during tensile test [13]. Serrated flow was observed in the stress-strain curve for tensile tests in the intermediate temperature range of 773-973 K.

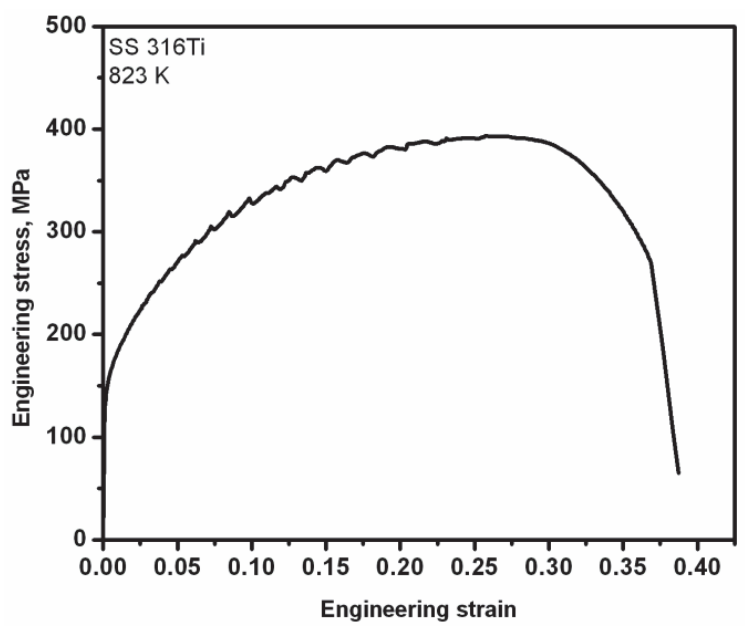

Figure 3: The engineering stress-strain curve of the steel obtained from tensile test at $823 \mathrm{~K}$.

\begin{tabular}{ccccc}
\hline Elastic modulus, & Yield stress, & Ultimate tensile & Uniform & Total \\
$\mathrm{MPa}$ & $\mathrm{MPa}$ & strength, $\mathrm{MPa}$ & elongation, $\%$ & elongation, $\%$ \\
154000 & 151 & 394 & 25.8 & 32.1 \\
\hline
\end{tabular}

Table 2: Tensile properties of the material at $823 \mathrm{~K}$ 
Pure fatigue tests were carried out on SS316Ti specimens at $823 \mathrm{~K}$ at different total strain amplitudes. The cyclic stress response of the alloy is shown in Fig. 4. The material showed continuous hardening followed by saturation for a brief time period and the decrease in peak stress due to the formation of macro-cracks. SS 316 and other grades of stainless steels are used in solution annealed condition; an initial hardening is quite expected during fatigue cycling in this material $[6,7,14]$. The initial hardening in this material generally occurs due to the dislocation generation and their mutual interactions as well as interactions between mobile dislocations and the solute atoms present in the matrix.

DSA during cyclic deformation is observed in the form of serrations in the hysteresis loops, Fig. 5. Various other manifestations include pronounced cyclic hardening, increase in stress response with increase in temperature, decrease in plastic strain with increasing temperature or decreasing strain rate (negative strain rate sensitivity) [15]. The influence of DSA on dislocation substructure in austenitic stainless steels has been studied by Rao et al. [16]. At room temperature, well developed dislocation cell structure was observed. However, in the DSA range, the tendency from cell to planar slip bands was observed $[16,17]$. It is interesting to note that the serrations in the hysteresis loop disappear slowly with cycling, Fig. 5. Similar observation has been reported by Goyal et al. on 316 LN SS at $873 \mathrm{~K}$ [18]. Sarkar et al. observed the DSA during LCF of 316 LN SS in the temperature range of 823-923 K [19].

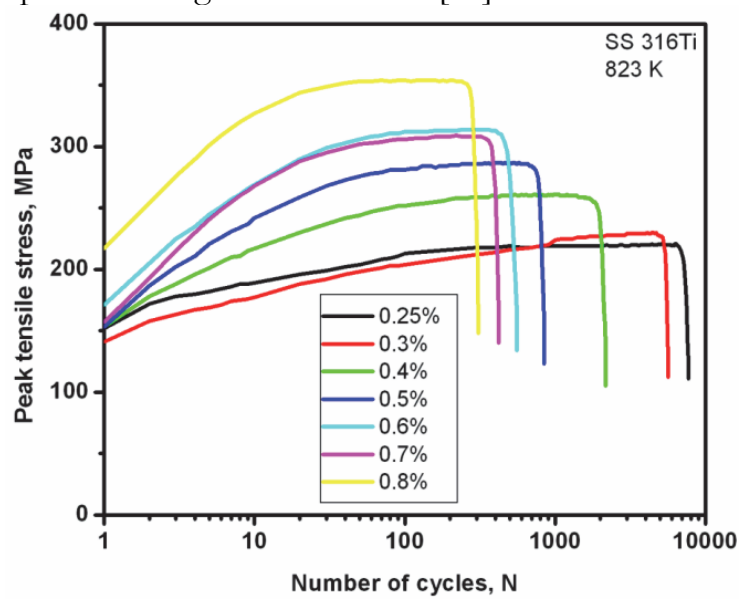

Figure 4: The cyclic stress response of $316 \mathrm{Ti}$ SS at $823 \mathrm{~K}$ under total strain controlled cycling.

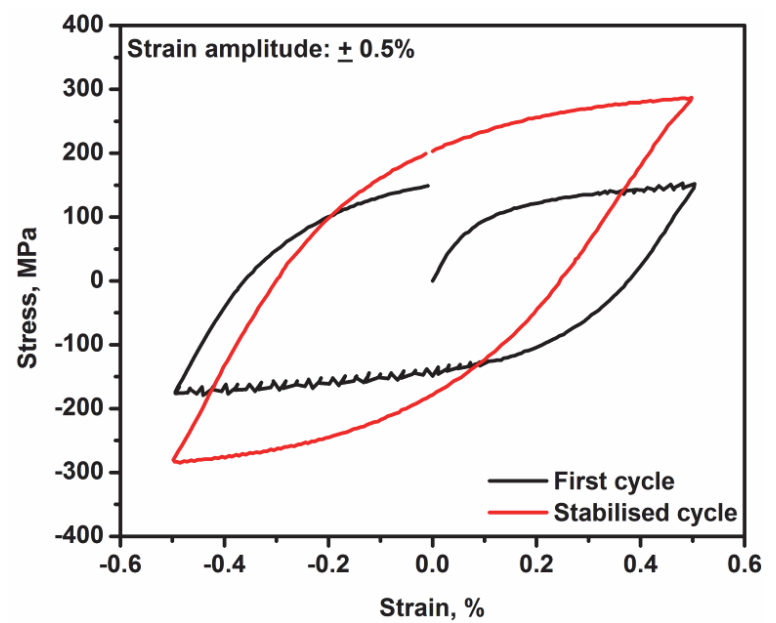

Figure 5: Occurrence of dynamic strain ageing during low cycle fatigue testing at $823 \mathrm{~K}$ and at strain amplitude of $\pm 0.5 \%$.

The influence of total strain amplitude on fatigue life of the material is shown in Fig. 6. The fatigue life decreased with increase in total strain amplitude. The variation of low cycle fatigue life with total, plastic and elastic strain amplitudes has been analyzed on the basis of strain-life relationship, which is defined by the following equation:

$$
\frac{\Delta \varepsilon_{t}}{2}=\frac{\sigma_{f}^{\prime}}{E}\left(2 N_{f}\right)^{b}+\varepsilon_{f}^{\prime}\left(2 N_{f}\right)^{c}
$$


where, $\Delta \varepsilon_{t}, N_{f}, \mathrm{E}, \sigma_{f}^{\prime}, \varepsilon_{f}^{\prime}, b, c$ are total strain range, fatigue life, Young's modulus, fatigue strength coefficient, fatigue ductility coefficient, fatigue strength exponent and fatigue ductility exponent respectively. The elastic and plastic strain amplitudes were obtained from the stabilized hysteresis loops at respective total strain amplitudes. The values for the coefficients for 316Ti SS determined from least square fit are given in Tab. 3.

Hardening characteristics exhibited by the material are reflected in the cyclic stress-strain behavior as shown in Fig. 7. From the locus of the stress-strain maxima of the stable hysteresis loops of different strain amplitudes, cyclic stress-strain curve can be represented by a power law equation as follows:

$$
\Delta \sigma / 2=K^{\prime}\left(\Delta \varepsilon_{p} / 2\right)^{n^{\prime}}
$$

where, $\Delta \sigma, \Delta \varepsilon_{p}, K^{\prime}, n^{\prime}$ are stress range, plastic strain range, cyclic strain hardening coefficient, cyclic strain hardening exponent, respectively. The value of $K^{\prime}$ and $n^{\prime}$ obtained by least square method is given in Tab. 3 .

\begin{tabular}{cc|cc|cc}
\hline \multicolumn{2}{r}{$\begin{array}{c}\text { Cyclic stress strain curve } \\
\text { coefficients }\end{array}$} & \multicolumn{2}{c}{ Basquin relation coefficients } & \multicolumn{2}{c}{$\begin{array}{c}\text { Coffin-Manson relation } \\
\text { coefficients }\end{array}$} \\
$K^{\prime}$ & $n^{\prime}$ & $\sigma_{f}^{\prime}$ & $b$ & $\varepsilon_{f}^{\prime}$ & $c$ \\
$1326 \mathrm{MPa}$ & 0.259 & $1052 \mathrm{MPa}$ & -0.147 & 0.13 & -0.51 \\
\hline
\end{tabular}

Table 3: Values of coefficients of strain-life relation for 316Ti SS

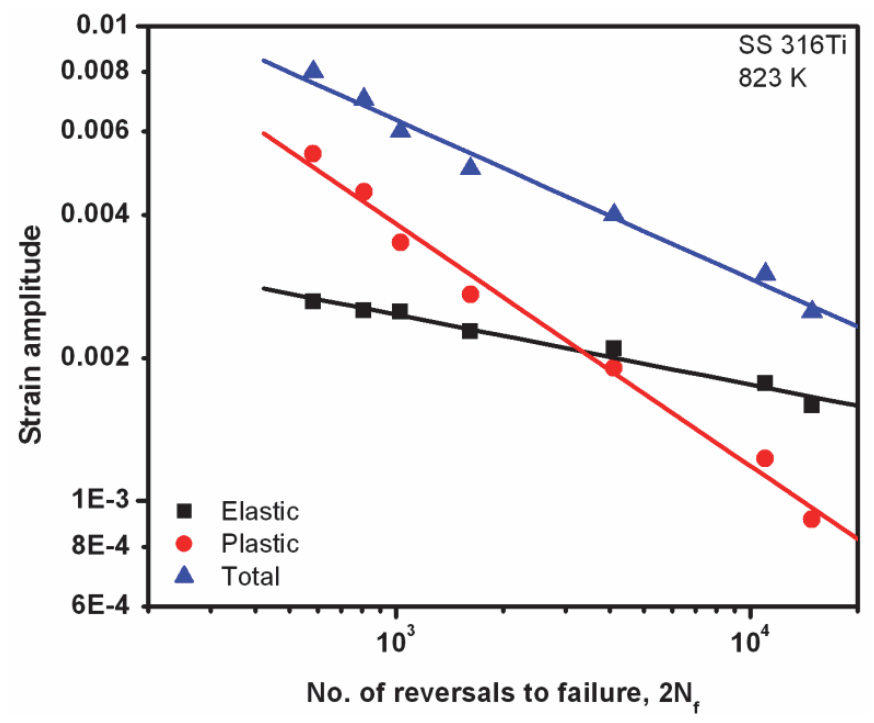

Figure 6: Strain- life plots for SS 316Ti at $823 \mathrm{~K}$.

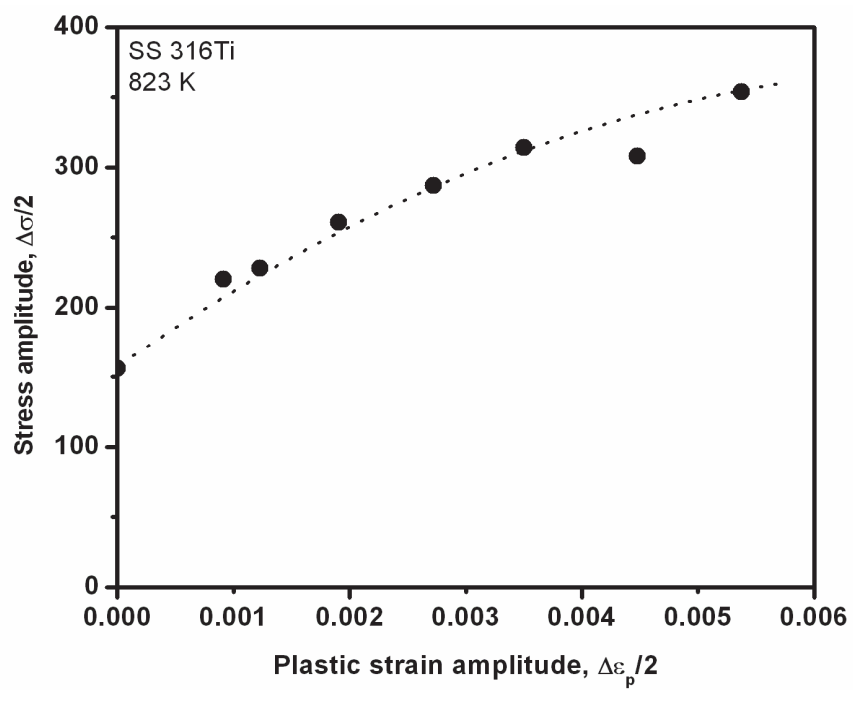

Figure 7: The cyclic stress-strain curve of SS $316 \mathrm{Ti}$ at $823 \mathrm{~K}$.

Fractographic studies conducted on failed fatigue tested samples revealed the crack initiation and propagation as transgranular, Figs. 8(a) and (b). Crack initiation occurred at surface connected slip bands and crack propagation is reflected by fatigue striations on fracture surface, Figs. 8(a) and (b), respectively. Transgranular crack propagation was observed for 1 minute tensile hold test also.

Since the LCF damage is mainly due to the accumulation of plastic strain, the hysteresis loop energy approach can provide accurate estimation of fatigue life of the material [20,21]. The relationship between fatigue life and hysteresis loop energy follows linear relationship on log-log plot and can be represented as power law relation

$$
\Delta W_{t}=A\left(2 N_{f}\right)^{b}
$$

where, $\Delta W_{t}$ is the strain energy density at half life, $2 N_{f}$ is the number of reversals to failure and $A$ and $b$ are material constants. The energy was calculated from the integration of hysteresis loop area at stabilization. The plot is shown in Fig. 9. The value of constants $A$ and $b$ were found to be 454.78 and -0.689 respectively. 

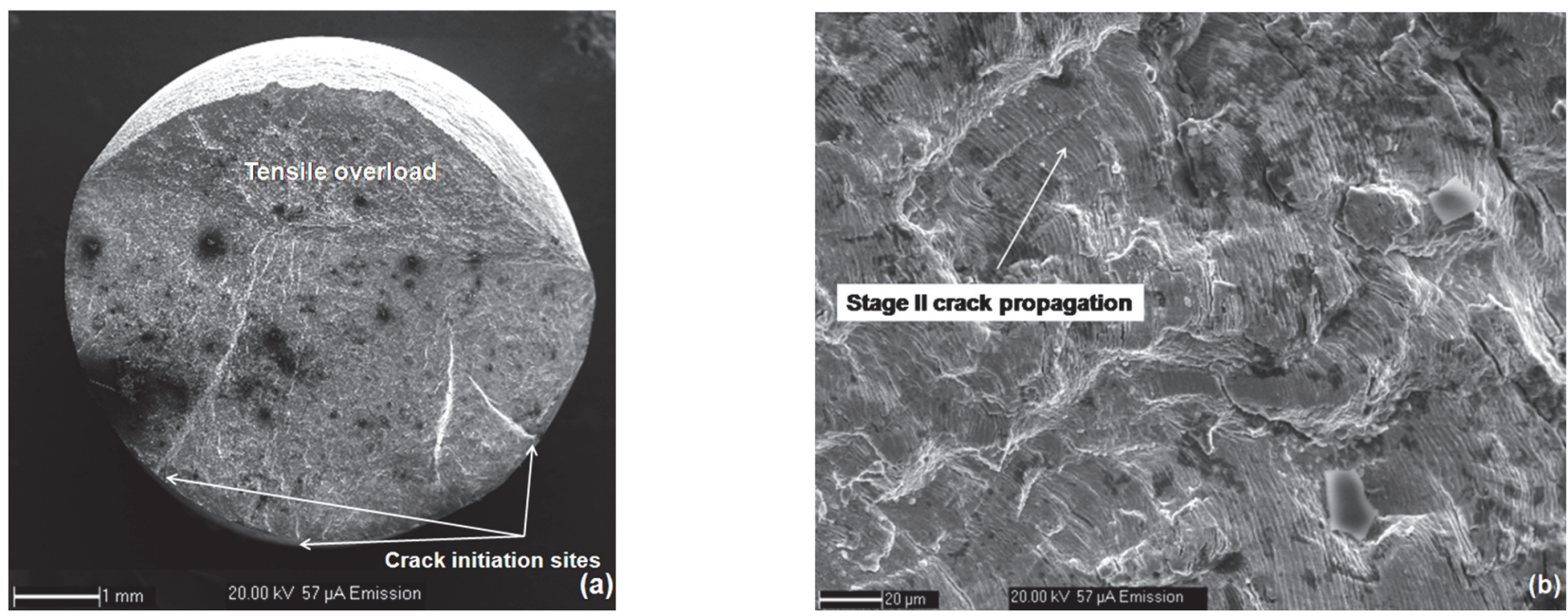

Figure 8: The fracture appearance of the fatigue tested specimen at $\pm 0.8 \%$ strain amplitude (a) crack initiation sites and (b) transgranular crack propagation in the material.

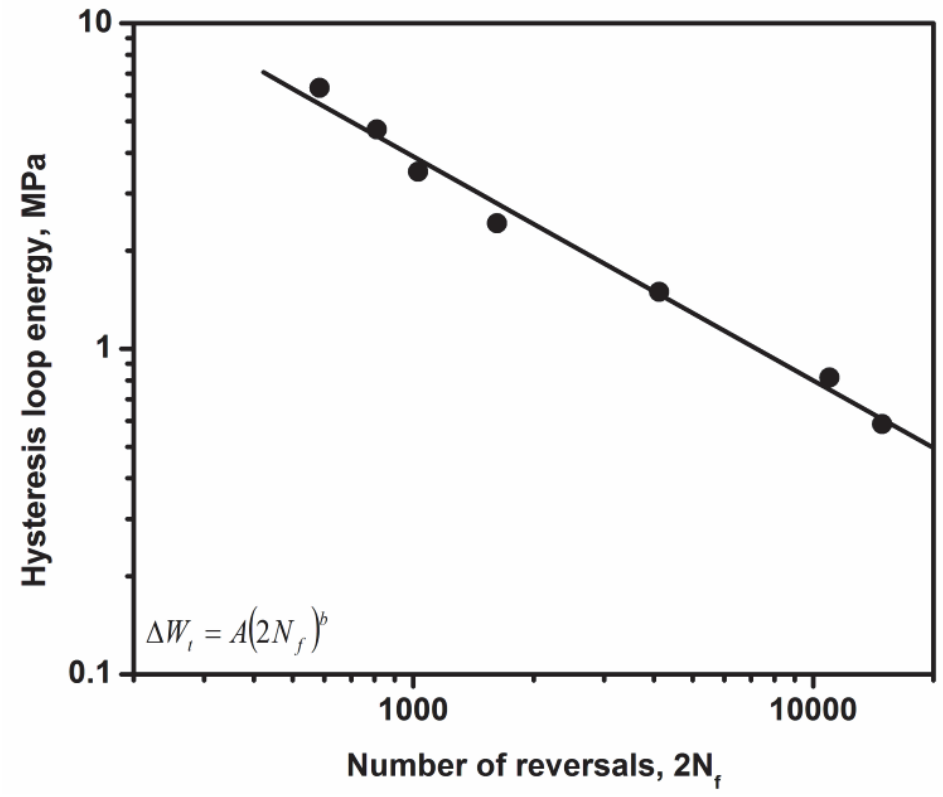

Figure 9: Variation of hysteresis loop energy as a function of number of reversals for 316Ti SS.

Creep-fatigue interaction test was conducted at strain amplitude of $\pm 0.4 \%$ with hold time of 1 minute in peak tensile strain. The stabilized hysteresis loops for continuous cycling with and without hold time are shown in Fig. 10. The fatigue life of the material decreased in presence of tensile hold compared to the continuous cycling at same strain amplitude $( \pm 0.4 \%)$ and temperature $(823 \mathrm{~K})$, Tab. 4.

The introduction of the hold time at maximum tensile strain allows for the conversion of elastic strain to plastic strain and results in the stress relaxation. The stress relaxation results from the creep deformation in the specimen resulting in creep cavitation on the grain boundaries. The amount of stress relaxation was found to be significantly lower than that of ferritic steels and superalloys, Tab. 4 [11,22]. The stress relaxation is generally found to occur from the creep deformation in the specimen interior that can result in cavities on grain boundaries. These internal grain boundary cavities interact with a propagating fatigue crack to result in an enhanced crack growth rate.

The material properties generated in these experiments are useful for design of bellows made of SS316 Ti as per RCC-MR design code for SFR applications. 


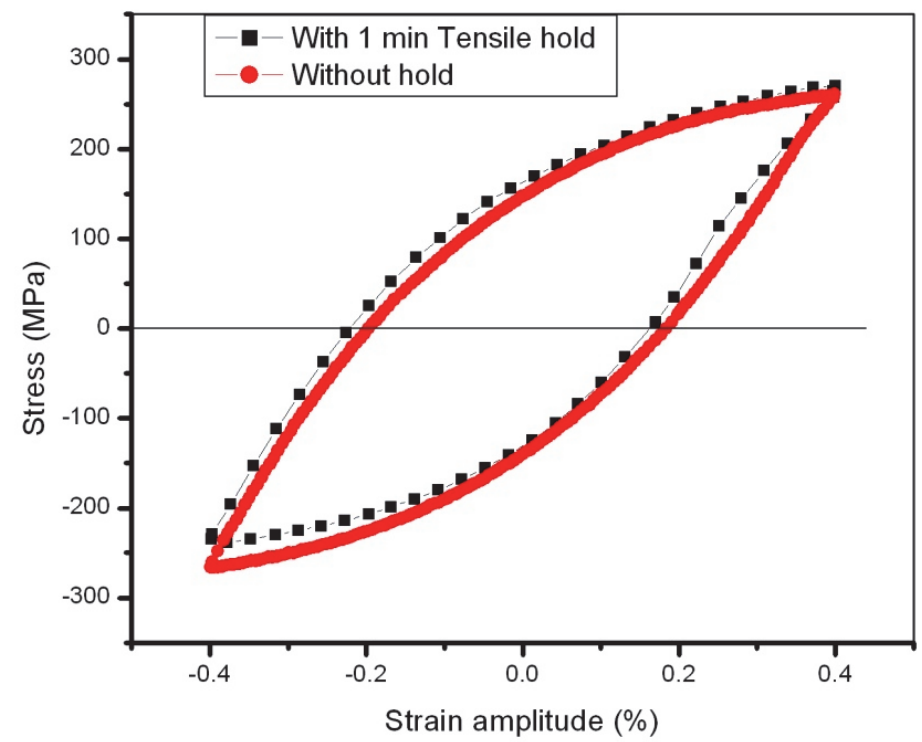

Figure 10: The stabilized hysteresis loop for $\pm 0.4 \%$ strain amplitude with and without hold.

\begin{tabular}{ccc}
\hline $\begin{array}{c}\mathrm{N}_{\mathrm{f}} \text { (continuous } \\
\text { cycling: } \pm 0.4 \%)\end{array}$ & $\begin{array}{c}\mathrm{N}_{\mathrm{f}}(1 \text { minute tensile } \\
\text { hold: } \pm 0.4 \%)\end{array}$ & $\begin{array}{c}\text { Amount of stress relaxed at } \\
\text { half life }\end{array}$ \\
2060 & 1735 & $9 \mathrm{MPa}$ \\
\hline
\end{tabular}

Table 4: Comparison of creep-fatigue life with continuous cycling

\section{CONCLUSIONS}

$\mathrm{B}$ ased on the investigation of low cycle fatigue and creep-fatigue interaction tests on SS316Ti at $823 \mathrm{~K}$, following conclusions can be drawn:

1. The material showed significant cyclic hardening followed by saturation and final fracture during cyclic loading.

2. The fatigue life decreased with increase in strain amplitude.

3. Dynamic strain ageing was observed in the material during initial cycles which disappeared with further cycling.

4. The creep-fatigue interaction life was found to be lower than that in pure fatigue experiment.

5. The tensile and fatigue data generated will be useful for the design of SS316Ti bellows.

\section{REFERENCES}

[1] Fontana M. G. (1987). Corrosion Engineering, McGraw Hill Book Company, Singapore.

[2] Kumar Krovvidi S.C.S.P., Padmakumar G. and Bhaduri A.K. (2017). Experience of various materials for design and manufacture of bellows for nuclear industry, J. Advance Mater. Proc., 2 pp. 156-161. DOI: 10.5185/amp.2017/305.

[3] Standards of Expansion Joint Manufacturer's Association (EJMA) - 10 th Edition, 2016.

[4] Design and construction rules for mechanical components for nuclear installations RCC-MRx, 2012.

[5] ASME Boiler and pressure vessel code, section-III, 2017.

[6] Srinivasan V.S., Valsan M., Rao K.B.S., Mannan S.L. and Raj B. (2003). Low cycle fatigue and creep-fatigue interaction behavior of 316L(N) stainless steel and life prediction by artificial neural network approach, Int. J. Fatigue, 25 pp. 13271338. DOI: $10.1016 / \mathrm{S} 0142-1123(03) 00064-1$.

[7] Rao K.B.S., Sandhya R. and Mannan S.L. (1993). Creep-fatigue interaction behaviour of type 308 stainless steel weld metal and type 304 stainless steel base metal, Int. J. Fatigue 15 pp. 221-229. DOI: 10.1016/0142-1123(93)90180-X. 
[8] Sandhya R., Rao K.B.S. and Mannan S.L. (2005). Creep-fatigue interaction behaviour of a 15Cr-15Ni, Ti modified austenitic stainless steel as a function of Ti/C ratio and microstructure, Mater. Sci. Engg. A 392 pp. $326-334$. DOI: $10.1016 /$ j.msea.2004.09.040.

[9] Zhang X., Tu S.T. and Xuan F. (2014). Creep-fatigue endurance of 304 stainless steels, Theo. Appl. Fract. Mech. 71 pp. 51-66. DOI: 10.1016/j.tafmec.2014.05.001.

[10] Goswami T. and Hanninen H. (2001). Dwell effects on high temperature fatigue damage mechanisms: Part II, Mater. Des. 22 pp. 217-236. DOI: 10.1016/S0261-3069(00)00061-3.

[11] Goyal S., Mariappan K., Shankar V, Sandhya R., Laha K. and Bhaduri A.K. (2018). Studies on creep-fatigue interaction behaviour of Alloy 617M, Mater. Sci. Engg. A 730 pp. 16-23. DOI: 10.1016/j.msea.2018.05.037.

[12] Rodriguez P. (1984). Serrated plastic flow, Bull. Mater. Sci. 6 pp. 653-663.

[13] Ganesan V., Laha K., Nandagopal M., Parameswaran P. and Mathew M.D. (2014). Effect of nitrogen content on dynamic strain ageing behaviour of type 316LN austenitic stainless steel during tensile deformation, Mater. High Temp. 31 pp. 162-170. DOI: 10.1179/1878641314Y.0000000009.

[14] Goyal S., Sandhya R., Valsan M. and Rao K.B.S. (2009). The effect of thermal ageing on low cycle fatigue behaviour of 316 stainless steel welds, Int. J. Fatigue 31 pp. 447- 454. DOI: 10.1016/j.ijfatigue.2008.07.006.

[15] Mannan S.L. (1993). Role of dynamic strain ageing in low cycle fatigue, Bull. Mater. Sci. 16 pp. 561-582. DOI: $10.1007 /$ BF02757656.

[16] Rao K.B.S., Valsan M., Sandhya R., Mannan S.L. and Rodriguez P. (1990). Manifestations of dynamic strain ageing during low cycle fatigue of type 304 stainless steel, Met. Mater. Proc. 2 pp. 17-36.

[17] Srinivasan V.S., Sandhya R., Rao K.B.S., Mannan S.L. and Raghavan K.S. (1991). Effects of temperature on the low cycle fatigue behaviour of nitrogen alloyed type 316L stainless steel, Int. J. Fatigue 13 pp. 471-478. DOI: 10.1016/0142-1123(91)90482-E.

[18] Goyal S., Mandal S., Parameswaran P., Sandhya R., Athreya C.N. and Laha K. (2017). A comparative assessment of fatigue deformation behavior of 316 LN SS at ambient and high temperature, Mater. Sci. Engg. A 696 pp. $407-415$. DOI: 10.1016/j.msea.2017.04.102.

[19] Sarkar A., Nagesha A., Sandhya R., Laha K. and Okazaki M. (2018). Manifestations of dynamic strain aging under low and high cycle fatigue in a type 316LN stainless steel, Mater. High Temp. 35 pp. 523- 528. DOI: $10.1080 / 09603409.2017 .1404684$.

[20] Kujawski D. (1989). Fatigue failure criterion based on strain energy density, Theoretical Appl. Mech. 7 pp. $15-22$.

[21] Roy S.C., Goyal S., Sandhya R. and Ray S.K. (2012). Low cycle fatigue life prediction of 316 L(N) stainless steel based on cyclic elasto-plastic response, Nucl. Eng. Des. 253 pp. 219- 225. DOI: 10.1016/j.nucengdes.2012.08.024.

[22] Shankar V., Mariappan K., Sandhya R., Laha K., Jayakumar T. and Kumar R.E. (2015). Effect of W and Ta on creepfatigue interaction behavior of reduced activation ferritic-martensitic (RAFM) steels, Fusion Eng. Des. 100 pp. $314-$ 320. DOI: 10.1016/j.fusengdes.2015.06.191. 